Demitri A. Cozanitis B SC PHARM MD,

Kaarlo Nuuttila MD,

J. Desmond Merrett PH D,

Risto Kala MD

\section{Influence of}

laryngoscope design on heart rate and rhythm changes during intubation
One hundred and twenty adult patients about to undergo surgery were premedicated with either meperidine or meperidine and atropine. After anaesthesia was induced with thiopentone and succinylcholine given, tracheal intubation was performed with the use of either a Magill or a Macintosh lap'ngoscope. There were no staristical differences in changes of heart rate and rhythm between the groups, as regards the type of premedication given or the design of laryngoscope used.

\section{Key words}

LARYNX: laryngoscopy, cardiac changes; PARASYMPATHETIC NERVOUS SYSTEM: atropine.

In 1943, Macintosh described his laryngoscope and noted that the exposure of the larynx was facilitated partly because the blade did not come into contact with the back surface of the epiglottis where the innervation is by the superior laryngeal nerve, a branch of the vagus. Rather, the blade fits into the angle made by the epiglottis with the base of the tongue, innervated by the glossopharyngeal nerve. Anaesthetists have long been taught that the use of the straight blade, e.g., the Magill or the Foregger, results in greater changes in cardiac rate and rhythm than seen with the use of the Macintosh blade.

From the Departments of Anaesthesia, Forssa District Hospital Forssa (Dr. Nuuttila) and Children's Hospital and Helsinki University Central Hospital (Drs. Cozanitis and Kala), Helsinki, Finland, and Department of Medical Statistics, The Queen's University of Belfast, Belfast, Northern Ireland (Dr. Merrett).

Address correspondence to: Dr. D.A. Cozanitis, Dept. of Anaesthesia, SF-00290 Helzinki 29, Finland.
Many studies pertaining to the effect that laryngoscopy has on heart rate and rhythm have been carried out but only one ${ }^{2}$ actually compared the two designs of laryngoscope blades on these parameters; the Macintosh had a greater effect on heart rate than did the straight blade. In that study, patients with pulmonary tuberculosis about to undergo thoracotomy were investigated whereas in the present study, only patients free of any disease that might produce changes in cardiac function were studied. It has been reiterated that the absence of anticholinergic drugs in premedication is associated with fewer cardiac cysrhythmias during the induction of anaesthesia. $^{3,4}$ Therefore, patients with and without atropine in their anaesthetic premedication were studied and tracheal intubation performed with either a Magill or a Macintosh laryngoscope in order to assess these differences on alterations of heart rate and rhythm

\section{Methods}

One hundred and twenty adult patients about to undergo minor surgery were allocated to the following four groups of 30 subjects each:

(a) Preoperative meperidine. Magill laryngoscope

(b) Preoperative meperidine + atropine. Magill laryngoscope

(c) Preoperative meperidine. Macintosh laryngoscope

(d) Preoperative meperidine + atropine. Macintosh laryngoscope

The doses of meperidine and atropine which were given intramuscularly (IM) 30 to 45 minutes before the start of anaesthesia were respectively, $1 \mathrm{mg} \cdot \mathrm{kg}^{-1}$ and $0.01 \mathrm{mg} \cdot \mathrm{kg}^{-1}$. Two operating theatres were used; in the first, a Magill laryngo- 
TABLE I Details of the patients studied

\begin{tabular}{llllll}
\hline & \multicolumn{2}{l}{ Magill } & & \multicolumn{2}{l}{ Macintosh } \\
\cline { 2 - 3 } \cline { 5 - 6 } & $\begin{array}{l}\text { Meperidine } \\
+ \text { atropine }\end{array}$ & Meperidine & $\begin{array}{l}\text { Meperidine } \\
+ \text { atropine }\end{array}$ & Meperidine \\
\hline No. of patients & 30 & 30 & 30 & 30 \\
Males (\%) & 30.0 & 20.0 & & 43.3 & 40.0 \\
Mean age $\pm \mathrm{SD}(\mathrm{yr})$ & $46 \pm 9.3$ & $44 \pm 13.1$ & & $44 \pm 13.1$ & $35 \pm 11.6^{*}$ \\
Mean weight $\pm(\mathrm{kg})$ & $74 \pm 14.0$ & $67 \pm 10.9$ & $74 \pm 15.2$ & $69 \pm 12.0$ \\
\hline
\end{tabular}

${ }^{*} \mathrm{p}<0.001$.

scope was available while the second theatre contained a Macintosh laryngoscope. Allocation to either of the theatres was on a purely random basis. Within each of these two groups, atropine was given on alternate days.

Only healthy patients were admitted to the study. Inclusion was based upon the patient's history, a careful preanaesthetic physical examination, twelve-lead electrocardiogram (ECG), chest radiogram, and lack of cardiac or anticholinergic drug therapy. Any patient with anatomical findings suggesting difficulties with tracheal intubation ${ }^{5}$ was excluded.

In the operating theatre, an intravenous infusion was established into which all drugs were instilled and the patient was oxygenated for three minutes. A single-lead ECG was continuously recorded on paper. The specific events which were noted on the paper by an assistant to ensure exact timing between the event and the ECG were: (1) immediately before the induction of anaesthesia with thiopentone $5 \mathrm{mg} \cdot \mathrm{kg}^{-1}$, given over 30 seconds; (2) following succinylcholine $1 \mathrm{mg} \cdot \mathrm{kg}^{-1}$ (injected when the eyelid reflex became suppressed) and ventilation of the lungs; (3) insertion of the laryngoscope blade into the mouth; (4) touching of the epiglottis (Magill) or the base of the tongue (Macintosh) i.e., laryngoscopy; (5) tracheal intubation; (6) inflation of the cuff; and (7) expansion of the lungs with oxygen.

No cricoid pressure was applied. The tracheal tube was lubricated with two per cent lidocaine gel and its cuff inflated to a pressure not exceeding $24 \mathrm{~cm} \mathrm{H}_{2} \mathrm{O}$, as measured by a specially designed gauge. After the lungs were expanded, the patient was connected to a mechanical ventilator. If any difficulty with intubation occurred, the patient was excluded from the study.

Mean heart rate was measured by averaging nine
$R-R$ intervals at the start of the times indicated above. Changes in cardiac rhythm, no matter how brief, were classified as dysrhythmias and noted.

The analysis of variance and the chi-square test were used for statistical analysis. $\mathrm{p}<0.05$ was taken as indicating significance.

\section{Results}

Table 1 shows that the four groups were not significantly different with respect to the number of males although this varied from 20.0 to 43.3 per cent. One group, Pre-operative meperidine. Macintosh, was significantly younger than the other three groups. The mean duration of laryngoscopy was from 16 to 19 seconds in the four study groups. The average time for inflating the cuff varied from 20 to 22 seconds.

The mean heart rates (beats/min) at each time of assessment are shown in Table II. The average pre-induction heart rates of the Magill group having received both meperidine and atropine was significantly higher than their counterparts with meperidine alone. The corresponding heart rate of this latter group was significantly lower than that of the Macintosh group with meperidine and atropine. Following preinduction, there were no statistically significant differences between the groups during any of the subsequent assessment periods. On the other hand the mean heart rates increased within each of the groups, $\mathrm{p}<0.05$.

Details of the cardiac dysrhythmias, predominantly unifocal ventricular extrasysoles and ventricular bigeminy, are given in Table III. The group, Pre-operative meperidine + atropine, Magill laryngoscope, had fewer changes in rhythm but the difference was not significant $\left(\chi^{2}=1.90\right.$, df $=3$, $0.70>p>0.50$ ). This group exhibited changes in rhythm during laryngoscopy but not during the 
TABLE II Mean heart rates (beats $/ \mathrm{min}$ ) in four patient groups

\begin{tabular}{lccccc}
\hline & \multicolumn{2}{l}{ Magill } & \multicolumn{3}{c}{ Macintosh } \\
\cline { 2 - 3 } \cline { 5 - 6 } & $\begin{array}{l}\text { Meperidine } \\
\text { + atropine }\end{array}$ & Meperidine & $\begin{array}{c}\text { Meperidine } \\
+ \text { atropine }\end{array}$ & Meperidine \\
\hline Pre-induction & 86.7 & 73.4 & 81.4 & 78.8 \\
& $(18.97)$ & $(14.43)$ & & $(14.24)$ & $(14.88)$ \\
After succinyl. and ventilation & 91.1 & 91.6 & & 94.8 & 88.4 \\
& $(14.86)$ & $(15.58)$ & & $(12.39)$ & $(18.16)$ \\
Laryngoscope blade in mouth & 89.5 & 92.8 & & 93.4 & 88.9 \\
& $(17.74)$ & $(15.41)$ & & $(12.85)$ & $(17.67)$ \\
Laryngoscopy & 92.5 & 96.9 & & 94.2 & 93.1 \\
& $(17.20)$ & $(14.15)$ & & $(12.54)$ & $(18.76)$ \\
Intubation & 96.6 & 99.5 & & 98.8 & 99.1 \\
Inflation of cuff & $(15.84)$ & $(16.31)$ & & $(13.67)$ & $(13.10)$ \\
Expansion of lungs & 99.5 & 103.1 & & 102.5 & 105.3 \\
& $(14.20)$ & $(14.99)$ & & $(14.13)$ & $(14.51)$ \\
& 101.7 & 102.9 & & 103.8 & 101.8 \\
& $(14.56)$ & $(13.46)$ & $(12.24)$ & $(15.38)$ \\
\hline
\end{tabular}

Between groups: Standard error of difference between two group means of each time $=3.92$ beats $/ \mathrm{min}$. Minimum significant difference $=8.0 \mathrm{beats} / \mathrm{min}$.

Within groups: Standard error of difference between two time means within each group $=2.30$ beats $/ \mathrm{min}$. Minimum significant difference $=4.7$ beats $/ \mathrm{min}$.

Standard deviations are given in brackets.

passage of the tracheal tube. Patients intubated with either laryngoscope showed alterations in heart rhythm with a similar frequency during inflation of the cuff and expansion of the lungs.

\section{Discussion}

Under the conditions of the study, the teaching that laryngoscopy performed with the Magill laryngoscope is more prone to changes in heart rate and rhythm is discounted. Neither do the results agree with the previous reports of a lesser incidence of these changes in patients not given on anticholinergic drug as premedication.

There is a decrease in the maximal heart rate occurring with age. One, therefore, could question whether the group, Pre-operative meperidine, Macintosh laryngoscope, which was significantly younger than the other groups would be comparable. However, after the pre-induction period, the mean heart rates of all groups did not differ significantly at any of the subsequent times (Table II). Thus, it is concluded that the autonomic nervous system behaved similarly in the four groups.
The average time needed for laryngoscopy ranged from 16 to 19 seconds and is similar to earlier studies, ${ }^{6.7}$ The effect of intubation on the mean arterial pressure becomes considerable when the duration exceeds 30 seconds. ${ }^{8}$ Nevertheless, in order to separate the relative contributions of laryngoscopy and tracheal intubation to the total pressure response, laryngoscopy should last from 30 to 45 seconds. $^{8}$ This infers that it is not reasonable to correlate the various changes in heart rate and rhythm with the events taking place at the exact moment for it would be possible that the result of the stimuli which the patient had received several seconds before would become apparent later.

The increase in heart rate during laryngoscopy and intubation, as compared to the preinduction rate, averaged from 20 to 25 beats $/ \mathrm{min}$. This change is similar to that described in other studies in patients without cardiac disease. ${ }^{6-9}$

Heart rate was unaffected by the inflation of the cuff. Cuff inflation required 20 to 22 seconds due to the use of the apparatus which enabled the pressure in the cuff to be controlled. Abou-Madi et al. ${ }^{10}$ purposely postponed the cuff inflation to observe 
TABLE IJI Incidence of dysrhythmias*

\begin{tabular}{|c|c|c|c|c|}
\hline \multirow[b]{2}{*}{ Presence of dysrhythmias } & \multicolumn{2}{|l|}{ Magill } & \multicolumn{2}{|l|}{ Macintosh } \\
\hline & $\begin{array}{l}\text { Meperidine } \\
+ \text { afropine } \\
6(20.0)\end{array}$ & $\begin{array}{l}\text { Meperidine } \\
10(33.3)\end{array}$ & $\begin{array}{l}\text { Meperidine } \\
+ \text { atropine } \\
10(33.3)\end{array}$ & $\begin{array}{l}\text { Meperidine } \\
10(33.3)\end{array}$ \\
\hline Laryngoscopy & 2 & - & - & - \\
\hline Intubation & - & 2 & 2 & 4 \\
\hline Inflation of cuff & 2 & 5 & $\xi$ & 3 \\
\hline Expansion of lungs & 4 & 3 & 4 & 4 \\
\hline
\end{tabular}

*Percentages in brackets

the effect of the filling on heart rate; an increase of 39 per cent was seen. In that study, 70 per cent of the patients had cardiovascular disease, which may have influenced the results.

In the only other sudy where laryngoscope blades of different design were compared, ${ }^{2}$ inflation of the cuff was done after the patient's heart rate and blood pressure had stabilised following tracheal intubation. There was no change in heart rate. Furthermore, the authors reported that the use of the Macintosh laryngoscope was accompanied by a greater effect on heart rate than that seen with the Magill blade and concluded that the result was due to the pressure of the instrument on the soft tissues of the anterior epiglottis. Wycoff, while also using a Macintosh blade, noted a similar change which was not present when the subjects were better sedated. ${ }^{11}$ Thus it is very probable that the patients in the present study were sufficiently anaesthetised so that no differences in heart rate between the laryngoscope groups became apparent. The report of Takeshima, et al. ${ }^{2}$ is thought not to be comparable to the current study. The premedications differ (Pantopon and minimal doses of atropine were used) and Takeshima et al. prolonged certain steps in order to examine the effects of the manoeuvres on the cardiovascular system; these delays may have provoked changes different from those occurring in the normal clinical situation. Finally, the patients all had pulmonary tuberculosis and perhaps reacted to the stress of laryngoscopy and intubation in a manner unlike that of our patients.

No dysrhythmia was considered clinically significant and the incidence was not excessive when compared to earlier reports. Katz and Bigger, ${ }^{12}$ reviewing various studies on the changes in heart rhythm curing laryngoscopy and intubation found the incidence of dysrhythmias to range from 0 to 90 per cent. The dysrhythmias reported are usually brief in duration and do not require treatment in the healthy well ventilated patient. The hypertensive patient, however, who develops S-T segment depression and $T$-wave inversion indicative of myocardial ischaemia, ${ }^{13}$ exemplifies the extent of the stimuli which are associated with larnygoscopy and tracheal intubation. Many methods have been proposed to control the noxious stimuli which place the individuals with cardiovascular or cerebrovascular conditions at great risk. These methods were summarised recently by Prys-Roberts: deep anaesthesia (inappropriate in the hypertensive patient), careful topical anaesthesia of pharynx and larynx (without use of laryngoscope), induction of anaesthesia with large doses of fentanyl, and betareceptor antagonistic therapy. ${ }^{14}$

The appearance of dysihythmias when the lungs were expanded may have been the result of earlier stimuli or, as suggested by Reirikainen and Pöntinen, ${ }^{15}$ to changes in the circulation from elevated intrathoracic pressure.

We found that laryngoscopy and tracheal intubation did not affect heart rate or rhythm differently if atropine was present or absent from the meperidine premedication, confirming earlier results. ${ }^{11,16}$ However, Mirakhur et al ${ }^{3}$ found that dysrhythmias were present only when an anticholinergic drug had becn given with meperidine. In common with us, they found that inflation of the cuff was associated with most of the dysrhythmias. The timing of premedication is the only explanation that can be offered for the origin of the different results of the two studies. In the present study premedication was given 30 to 45 minutes before induction of anaesthesia but 90 minutes preinduction in the earlier 
study. Patients who had received either only atropine or saline 30 minutes before induction of anaesthesia ${ }^{4}$ had a similar degree of change in heart rate from before induction to cuff inflation as we observed. It is very likely that the higher preinduction heart rates of patients having had only atropine, as compared to the present study, resulted from no sedative or narcotic drug being given. This might also explain why their patients which received only atropine as premedication demonstrated changes in cardiac rhythm.

In conclusion, the changes in heart rate and rhythm of patients free of cardiac disorders, intubated with either a Magill or a Macintosh laryngoscope are similar regardless of whether meperidine $1 \mathrm{mg} \cdot \mathrm{kg}^{-1}, 30$ to 45 minutes before the induction of anaesthesia, was given alone or with atropine $0.01 \mathrm{mg} \cdot \mathrm{kg}^{-1}$.

\section{References}

1 Macintosh $R R$. A new laryngoscope. Lancet 1943; 1: 205.

2 Takeshima K, Noda K, Higaki M. Cardiovascular response to rapid anaesthesia induction and endotracheal intubation. Anesth Analg $1964 ; 43: 201-8$.

3 Mirakhur RK, Clarke RSJ, Elliout J, Dundee JW. Atropine and glycopyrronium premedication: $A$ comparison of the effects on cardiac rate and thythm during induction of anaesthesia. Anaesthesia 1978; 33: $906-12$.

4 Fassoulaki $A$, Kaniaris $P$. Does atropine premedication affect the cardiovascular response to laryngoscopy and intubation? Br J Anaesth 1982; 54: $1065-8$.

5 Cass $N M$, James $N R$, Lines $V$. Difficult direct laryngoscopy complicating intubation for anaesthesia. Br Med J 1956; 1: 488-9.

6 Forbes AM, Dally FG. Acute bypertension during induction of anaesthesia and endotracheal intubation in normotensive man. Br J Anaesth 1970; 42: 618-24.

7 Kautto $U-M$, Heinonen $J$. Attenuation of circulatory response to laryngoscopy and tracheal intubation: A comparison of two methods of topical anaesthesia. Acta Anaesthesiol Scand 1982; 26: $599-602$.

8 Stoelting $R K$. Circulatory changes during direct laryngoscopy and tracheal intubation. Anesthesiology $1977 ; 47$ : 381-4

9 Kauito $U \cdot M$. Effects of precurarization on the blood pressure and heart rate changes induced by suxamethonium facilitated laryngoscopy and intubation. Acta Anaesthesiol Scand 1981; 25: 391-6.

10 Abou-Madi M, Keszler H, Yacaub O. A method for prevention of cardiovascular reactions to laryngoscopy and intubation. Can Anaesth Soc J 1975; 22: $316-29$.

11 Wycoff $C C$. Endotracheal intubation: Effects on blood pressure and heart rate. Anesthesiology 1960; 21: $153-8$.

12 Katz RL, Bigger Jr JT. Cardiac arthythmias during anesthesia and operation. Anesthesiology 1970; 33: 193-213.

13 Prys-Roberts $C$, Greene LT, Meloche $R$, Foëx $P$. Studics of anacsthesia in relation to hypertension. II. Haemodynamic conseqences of induction and endotracheal intubation. Br J Anaesth 1971; 45: 531-46.

14 Prys-Roberts $C$. Anaesthesia for the hypertensive patient. Proceedings of the 11 th International Postgraduate Course Vienna, 20-24 June, 1983, 27-34.

15 Reinikainen M, Pöntinen $P$. On Cardiac arhythmias during anaesthesia and surgery. Acta Med Scand 1966; Suppl 457, 1-36.

16 Middleton $M J$, Zitzer $J M$, Urbach $K F$. Is atropine always necessary before general anesthesia? Anesth Analg 1967; 46: 51-5.

Résumé

Cent-vingt patients devant subir une chirurgie ont été prémédiqués avec de la mépéridine ou de la mépéridine et de l'atropine. Ensuite on débutait l'anesthésie avec du thiopental et de la succinylcholine puis on procédait à l'intubation endotrachéale avec une lame Macintosh ou une lame Magill. Il n'y a eu aucune différence signifcative dans les changements de la fréquence et du rythme cardiaque dans les différents groupes peu importe le type de prémédication ou le type de lame urilisé. 